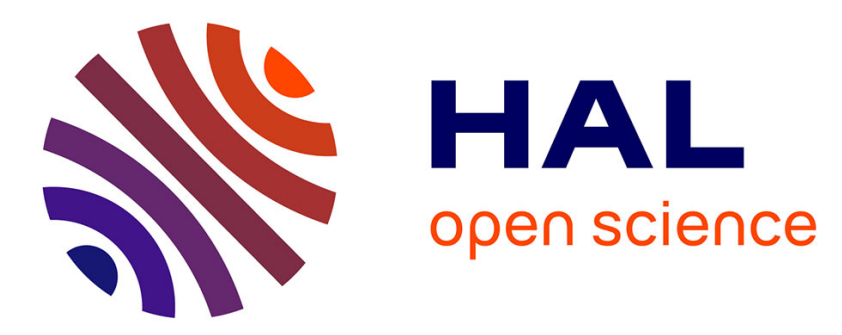

\title{
Investigating photoluminescence properties of Ca-doped ZnS nanoparticles prepared via hydrothermal method
}

\author{
Abdelghafour Said Messalti, Malika El-Ghozzi, Daniel Zambon, Rachid
} Mahiou, Zouaoui Setifi

\section{- To cite this version:}

Abdelghafour Said Messalti, Malika El-Ghozzi, Daniel Zambon, Rachid Mahiou, Zouaoui Setifi. Investigating photoluminescence properties of $\mathrm{Ca}$-doped $\mathrm{ZnS}$ nanoparticles prepared via hydrothermal method. Journal of Luminescence, 2021, 238, 10.1016/j.jlumin.2021.118227 . hal-03445530

\author{
HAL Id: hal-03445530 \\ https://hal.science/hal-03445530
}

Submitted on 24 Nov 2021

HAL is a multi-disciplinary open access archive for the deposit and dissemination of scientific research documents, whether they are published or not. The documents may come from teaching and research institutions in France or abroad, or from public or private research centers.
L'archive ouverte pluridisciplinaire HAL, est destinée au dépôt et à la diffusion de documents scientifiques de niveau recherche, publiés ou non, émanant des établissements d'enseignement et de recherche français ou étrangers, des laboratoires publics ou privés. 


\section{Journal Pre-proof}

Investigating photoluminescence properties of Ca-doped ZnS nanoparticles prepared via hydrothermal method

Abdelghafour Said Messalti, Malika El-Ghozzi, Daniel Zambon, Rachid Mahiou, Zouaoui Setifi

PII: S0022-2313(21)00343-4

DOI: https://doi.org/10.1016/j.jlumin.2021.118227

Reference: $\quad$ LUMIN 118227

To appear in: Journal of Luminescence

Received Date: 26 October 2020

Revised Date: 28 April 2021

Accepted Date: 19 May 2021

Please cite this article as: A.S. Messalti, M. El-Ghozzi, D. Zambon, R. Mahiou, Z. Setifi, Investigating photoluminescence properties of Ca-doped ZnS nanoparticles prepared via hydrothermal method, Journal of Luminescence, https://doi.org/10.1016/j.jumin.2021.118227.

This is a PDF file of an article that has undergone enhancements after acceptance, such as the addition of a cover page and metadata, and formatting for readability, but it is not yet the definitive version of record. This version will undergo additional copyediting, typesetting and review before it is published in its final form, but we are providing this version to give early visibility of the article. Please note that, during the production process, errors may be discovered which could affect the content, and all legal disclaimers that apply to the journal pertain.

(C) 2021 Published by Elsevier B.V. 


\section{CRediT authorship contribution statement}

A.S. Messalti : Investigation, Data curation, Writing - original draft

M. El-Ghozzi : Data curation, Formal analysis, Visualization, Validation

D. Zambon : Supervision, Validation, Visualization, Project administration, Writing - review \& editing

R. Mahiou : Data curation, Formal analysis, Visualization, Validation

Z. Setifi : Supervision, Validation, Visualization, Project administration, Funding acquisition. 


\title{
Investigating photoluminescence properties of Ca-doped $\mathrm{ZnS}$ nanoparticles prepared via hydrothermal method
}

\author{
Abdelghafour Said Messalti a,b,c*, Malika El-Ghozzi c , Daniel Zambon ${ }^{\text {c* }}$, Rachid Mahiou ${ }^{c}$, \\ Zouaoui Setifi ${ }^{b}$ \\ a Département de Physique, Faculté des Sciences, Université Ferhat Abbas Sétif 1, Sétif 19000, \\ Algeria. \\ ${ }^{\mathrm{b}}$ Laboratoire de Chimie, Ingénierie Moléculaire et Nanostructures (LCIMN), Université Ferhat \\ Abbas Sétif 1, Sétif 19000, Algeria. \\ c Université Clermont Auvergne, Institut de Chimie de Clermont-Ferrand, UMR 6296 \\ CNRS/UBP/Sigma Clermont, TSA 60026 CS 60026, F-63000 Clermont-Ferrand, France. \\ *E-mail address : daniel.zambon@uca.fr (corresponding author).
}

abdelghafour-messalti@ hotmail.com (corresponding author)

\begin{abstract}
The structural, morphological and optical properties of pure and Ca-doped zinc sulfide (ZnS:Ca) nanoparticles (NPs) prepared by hydrothermal method at different percentages of $\mathrm{Ca}$ are reported herein. The resulting NPs were characterized by X-ray diffraction analysis (XRD), Raman scattering, scanning electron microscopy (SEM), transmission electron microscopy (TEM) and photoluminescence (PL) spectroscopy. The XRD patterns confirmed the crystalline nature of all pure and doped NPs showing a single phase cubic blende structure, whereas the
\end{abstract}


SEM micrographs showed sphere-shaped NPs. The sizes of the as-prepared NPs estimated by TEM were found to be in the range $44-147 \mathrm{~nm}$. The PL emission spectra of ZnS:Ca nanocrystals excited at $400 \mathrm{~nm}$ consist of a broad band $(420 \mathrm{~nm}-640 \mathrm{~nm})$ characterized by two main contributions peaking at 484 and $533 \mathrm{~nm}$. The overall maximum emission intensity is found for $\mathrm{ZnS}: 3 \%$ Ca with internal quantum yield of $8.4 \%$.

Keywords: Hydrothermal synthesis; Ca-doped ZnS nanoparticles; Photoluminescence.

\section{Introduction}

The investigation on physico-chemical properties of Nanoparticles (NPs) has gained considerable attention since several years thanks to their potential application in the fabrication of nano-devices. Due to their large surface on volume ratio and quantum confinement effects, the electronic, magnetic and optical properties of NPs get appreciably modified compared to their bulk counterparts [1-4] since the number of active sites occupying the surface area increases with decrease in the particle size.

Mostly, NPs have been prepared from II-VI and from III-V semiconductor groups. These inorganic materials show very important advantages due to their chemical stability and long service life. Among these, zinc sulfide (ZnS) is a typical II-VI semiconductor compound with direct bandgap energy of $3.65 \mathrm{eV}$ and a small Bohr radius [5]. Because of its outstanding luminescence and photochemical properties, $\mathrm{ZnS}$ is a potential candidate for solar cells [6], nuclear batteries [7], optoelectronic devices [8], light - emitting diodes (LED) [9] and as sample for bio-sensing and bio-imaging [10-12]. 
A doping protocol is one of the most intensively utilized means to improve targeted optical, electronic, photocatalytic and textural properties of semiconducting nanomaterials by inserting traps and discrete energy states into the stimulated electrons bandgap. Doping will increase structural defects, modify grain size and increase the contact surface area, which is expected to lead to higher quantum yields for semiconductor materials. Series of $\mathrm{ZnS}$ nanocrystals doped with different transition metal (TM) or rare-earth metal (RE) ions have been described in literature. Lin et al synthesized $\mathrm{ZnS}$ : $\mathrm{Cu}, \mathrm{ZnS}$ : $\mathrm{Ag}$ and $\mathrm{ZnS}$ : Au materials using a chemical method [13]; F. Amirian et al studied ZnS: TM [14] and D. Kakoti et al which reported the optical properties of $\mathrm{ZnS}: \mathrm{Sm}^{3+}$ [15]. However, only one paper was found in the literature indicating the effect of $\mathrm{Ca}^{2+}$ as dopant on the luminescence properties of $\mathrm{ZnS}$ nanoparticles [16]. Despite that the authors report an enhancement of the luminescence of $\mathrm{ZnS}: \mathrm{Ca}^{2+}$ measured on nanoparticles dispersed in methanol under UV excitation at $310 \mathrm{~nm}$, no attention has been paid on the effect and the mechanism of $\mathrm{Ca}^{2+}$ ion doping in these $\mathrm{ZnS}$ phosphors, notably from the crystallographic point of view, and from the analysis of excitation spectra and kinetics of the luminescence. Same considerations concern recent works on $\mathrm{ZnO}$ :Ca NPs where it has been shown that such doping by $\mathrm{Ca}^{2+}$ can improve the optical properties of $\mathrm{ZnO}$ undoped NPs $[17,18]$. Hence, $\mathrm{Ca}^{2+}$ is a motivational candidate for investigating its effect of luminescence properties.

Several techniques such as chemical vapour deposition, wet chemical route, coprecipitation, solvothermal or hydrothermal processes, thermal decomposition method, radio frequency magnetron sputtering technique and solid state reaction method were used by many researchers to prepare ZnS NPs [19]. Among them the hydrothermal process, which is ecofriendly because of the use of water as a solvent and an inorganic salt as a catalyst for the reaction, appears very suitable due to its ease and high efficiency. Moreover the reagents are non- 
toxic and inexpensive. The hydrothermal protocol is widely used as one of the aqueous-phase processes and collected crystals show a strong purity and reasonable dispersion. Besides its benefit stems from higher reliability and the process itself is fast and needs a small thermal supply only. Collection of studies on hydrothermally synthesized $\mathrm{ZnS}$ based materials were recently published concerning for instance photo-catalytic or photo-luminescent properties $[20,21]$. Thus this method was used in the present work for the production of $\mathrm{ZnS}$ and Ca-doped ZnS NPs at different concentrations $(1.5 ; 3 ; 4.5$ and $6 \mathrm{~mol} \%)$.

The choice of $\mathrm{Ca}^{2+}$ doping for $\mathrm{ZnS}$ NPs is motivated in order to modify the structural properties connected with the zinc environment and see their influence on optical properties. $\mathrm{Ca}^{2+}$ ionic radius is higher than that of $\mathrm{Zn}^{2+}, 1.00 \AA$ (in a 4-fold coordination) [22] versus $0.60 \AA$ (for a 6-fold coordination) [22] and calcium sulphide CaS has rock salt structure with a bandgap energy of $4.8 \mathrm{eV}$. These differences in physical properties are expected to provide new insights, notably in the target of the production of very efficient Light Emitting Diodes (LEDs) for industrial use.

We report in this paper the undoped and $\mathrm{Ca}^{2+}$ doped $\mathrm{ZnS}$ NPs synthesis protocol. The impact of $\mathrm{Ca}^{2+}$ ions as a dopant factor on structural, textural and optical properties was investigated. The materials characterization was followed using different techniques such as $\mathrm{X}$ Ray diffraction (XRD), Raman scattering spectroscopy, Scanning Electron Microscopy (SEM) and Transmission Electron Microscopy (TEM). In addition, photoluminescence measurements allowed us to carry out a complete study of the influence of $\mathrm{Ca}^{2+}$ ions doping. 


\section{Experimental}

\subsection{Materials}

Zinc acetate dihydrate $\left(\mathrm{Zn}\left(\mathrm{CH}_{3} \mathrm{COO}\right)_{2}, 2 \mathrm{H}_{2} \mathrm{O}\right)$, thiourea $\left(\mathrm{SC}\left(\mathrm{NH}_{2}\right)_{2}\right)$ and calcium chloride dihydrate $\left(\mathrm{CaCl}_{2}, 2 \mathrm{H}_{2} \mathrm{O}\right)$ were purchased from Sigma-Aldrich and used without further purification. Deionized water (DI) was used for the synthesis.

\subsection{Synthesis of undoped and $\mathrm{Ca}^{2+}$ doped $\mathrm{ZnS}$}

Undoped and $\mathrm{Ca}^{2+}$ doped $\mathrm{ZnS}$ NPs were synthesized by a hydrothermal method. In a typical procedure for undoped $\mathrm{ZnS}$ materials, $2.94 \mathrm{~g}(13 \mathrm{mmol})$ of $\mathrm{Zn}\left(\mathrm{CH}_{3} \mathrm{COO}\right)_{2}, 2 \mathrm{H}_{2} \mathrm{O}$ and $2.44 \mathrm{~g}(32 \mathrm{mmol})$ of $\mathrm{SC}\left(\mathrm{NH}_{2}\right)_{2}$ powders were dissolved separately in $20 \mathrm{ml}$ of deionized water with continuous stirring. A $\mathrm{Zn} / \mathrm{S}$ initial molar ratio of $1 / 2.5$, thus corresponding to a sulfur excess compared with the desired formula, was chosen according to the literature [23]. A $\mathrm{Zn} / \mathrm{S}$ molar ratio of $1 / 1$ corresponding to the desired stoichiometric formula was also tested, but the experimental yield (around 20-25\%) was very low compared to that found with the 1/2.5 molar ratio (about $60 \%$ ). Then, the solutions were mixed by adding the $\mathrm{SC}\left(\mathrm{NH}_{2}\right)_{2}$ solution drop by drop into the $\mathrm{Zn}\left(\mathrm{CH}_{3} \mathrm{COO}\right)_{2}, 2 \mathrm{H}_{2} \mathrm{O}$ solution with vigorous stirring for $30 \mathrm{mn}$. The final solution was transferred to a $100 \mathrm{ml}$ Teflon-lined stainless steel autoclave which was kept at $180{ }^{\circ} \mathrm{C}$ for $20 \mathrm{~h}$. After that the solution was centrifuged and the residue was recovered. The product was washed several times with deionized water and ethanol followed by centrifuging at $4000 \mathrm{rpm}$ for $20 \mathrm{~min}$. The resulting final product was kept for drying in an oven for $12 \mathrm{~h}$ at $80^{\circ} \mathrm{C}$ to yield $\mathrm{ZnS}$ NPs.

The same synthesis protocol including excess of sulfur was used for the $\mathrm{Ca}^{2+}$ doped $\mathrm{ZnS}$ materials with the nominal formula $\mathrm{Zn}_{1-\mathrm{x}} \mathrm{Ca}_{\mathrm{x}} \mathrm{S}$ (with $\mathrm{x}=1.5 ; 3 ; 4.5 ; 6$ mol \%), later named $\mathrm{ZnS}: \mathrm{x}$ $\% \mathrm{Ca}$. For this purpose, the zinc acetate solution was replaced by a $\mathrm{Zn} / \mathrm{Ca}$ mixed solution 
obtained by adding drop by drop a solution of $\mathrm{x} \mathrm{mmol} \mathrm{of} \mathrm{CaCl}_{2}, 2 \mathrm{H}_{2} \mathrm{O}$ in $5 \mathrm{~mL} \mathrm{H}_{2} \mathrm{O}$ in a solution of (1-x) mmol of zinc acetate in $20 \mathrm{~mL} \mathrm{H}_{2} \mathrm{O}$ with continuous stirring for $10 \mathrm{mn}$.

\subsection{Characterization techniques}

\subsubsection{Structural and morphological characterizations}

The X-ray powder diffraction (XRD) patterns were recorded with a Philips X-Pert Pro diffractometer equipped with an $\mathrm{X}^{\prime}$ Celerator detector and using $\mathrm{Cu}-\mathrm{K} \alpha_{1,2}$ radiation. Data were collected at room temperature in the range from $10.0^{\circ}$ to $75.0^{\circ}(2 \theta)$ with a step width of $0.02^{\circ}$ (20). All the data were processed by Xpert High Score Plus software using databases (unit cell parameters, peaks identification). Particle size measurements were carried out using Scherrer formula. The surface morphology of the as-prepared NPs was recorded using scanning electron microscopy with a JEOLJSM-7001f device. SEM micrographs were performed using a high vacuum at $20 \mathrm{kV}$ and a back-scatter electron detector. Transmission Electronic Microscopy (TEM) images were recorded on a Hitachi H-7650 microscope at the Centre Imagerie Cellulaire Santé (CICS) of Clermont-Ferrand University.

Polycrystalline samples Raman spectra were recorded at room temperature with a $\mathrm{T}$ 64000 JOBIN- YVON spectrometer equipped with a CCD detector cooled with liquid nitrogen. Excitation at $532 \mathrm{~nm}$ was supplied with a compact doubled YAG:Nd ${ }^{3+}$ Oxxius laser. The samples were placed under the X50 objective of an Olympus microscope allowing probing a surface of 2 $\mu^{2}$. A unique measurement cycle was performed for each sample with an acquisition time of $120 \mathrm{~s}$. 


\subsubsection{Luminescence analysis}

The optical properties were investigated by recording the luminescence spectra with a Horiba-Jobin-Yvon set-up consisting of a Xenon lamp operating at $400 \mathrm{~W}$ monochromatized through Triax 180 then the emitted light was dispersed through Triax 550 and detected with the means of a cryogenically cold charge coupled device (CCD) camera (Symphony LN2 series) for emission spectra and Hamamatsu R928 PMT for excitation ones. Temporal evolution of the luminescence were carried out with a pulsed Nd:YAG OPO-Ekspla NT342B laser (3-5 ns pulse duration, $10 \mathrm{~Hz}, 5 \mathrm{~cm}^{-1}$ line width, $210-2600 \mathrm{~nm}$ ). The emitted photons were detected at right angle from the excitation and analyzed through Edinburgh FLS980 spectrometer (1200 groove $\mathrm{mm}^{-1}$ grating, blazed at $500 \mathrm{~nm}$, minimum band-pass of $0.1 \mathrm{~nm}$ ) equipped with Hamamatsu R928P PMT (200-870 nm).

The internal and external quantum yields (QY) were assessed using a C9920-02G PL-QY measurement system from Hamamatsu. The setup comprises a 150W monochromatized Xe lamp, an integrating sphere (Spectralon ${ }^{\circledR}$ Coating, $\varnothing=3.3$ inch) and a high sensitivity CCD spectrometer for detecting the whole spectral luminescence (the emission spectra were integrated from $400 \mathrm{~nm}$ to $650 \mathrm{~nm}$ for $\mathrm{ZnS}$ and $\mathrm{ZnS}$ : Ca compounds). The automatically controlled excitation wavelength range spread from $250 \mathrm{~nm}$ to $950 \mathrm{~nm}$ (deliberately limited from 300 to 450 $\mathrm{nm}$ in this study) with a resolution bandwidth better than $5 \mathrm{~nm}$. Quantum yields excitation spectra were obtained by scanning the excitation and monitoring the overall luminescence. The internal efficiencies correspond to the ratio between the emitted and absorbed photons. All measurements were recorded at room temperature. 


\section{Results and discussion}

\subsection{XRD analysis}

The X-ray diffraction patterns of undoped and $\mathrm{Ca}^{2+}(1.5,3,4.5$ and 6 mol \%) doped $\mathrm{ZnS}$ NPs are reported in Fig. 1. Whatever the $\mathrm{Ca}^{2+}$ content into the $\mathrm{ZnS}$ host, these patterns match very well with the JCPDS card 80-0020 corresponding to the cubic blende $\mathrm{ZnS}$ structure. No additional diffraction peaks corresponding to the $\mathrm{ZnS}$ wurtzite polymorph or secondary phases are present, confirming the validity of the synthesis protocol and that prepared samples are pure in structural form.

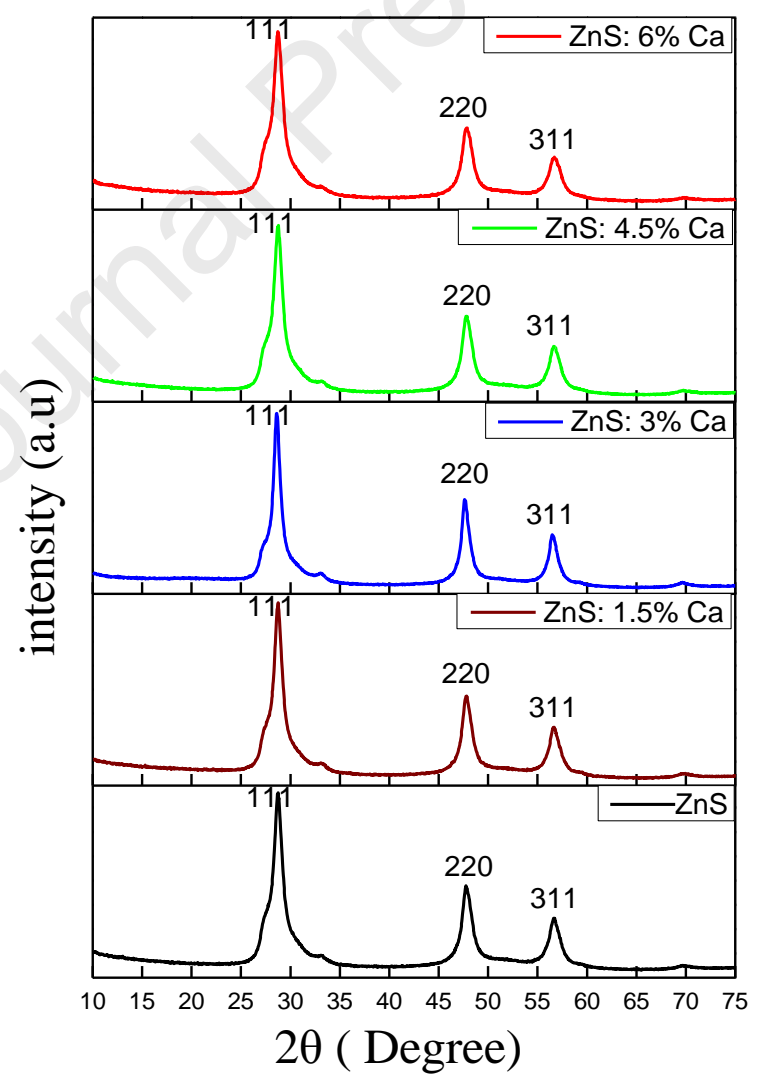

Fig. 1: XRD patterns of $\mathrm{ZnS}$ and $\mathrm{ZnS}: \mathrm{x} \% \mathrm{Ca}$ NPs. 
Interestingly there is no significant shifting in the diffraction peaks position. In the $\mathrm{ZnS}$ blende structure, the $\mathrm{Ca}^{2+}$ ions cannot accommodate the characteristic 4-fold cationic coordination due to their ionic radius significantly higher than that of $\mathrm{Zn}^{2+}$ ions [22]. Thus they cannot be incorporated in cubic blende crystallographic sites 4(a). However $\mathrm{Ca}^{2+}$ ions can adopt a 6-fold coordination. This feature suggests that $\mathrm{Ca}^{2+}$ ions can be incorporated into specific interstitial sites initially vacant in the blende structure ( $4 d$ sites $(x / a=1 / 4 ; y / b=3 / 4 ; z / c=1 / 4)$, see Fig. 2$)$ as demonstrated by $D$. K. Sen et al [24]. Besides, from the ZnS-CaS binary system investigation, no secondary phases are observed taking into account the studied $\mathrm{Ca} / \mathrm{Zn}$ stoichiometric amounts [25].

Due to these statements, vacancies are created in $4 \mathrm{a}$ sites $\left(\mathrm{Zn}^{2+}\right.$ sites $)$ due to $\mathrm{Ca}^{2+}$ vicinity, which play a very important role in photoluminescence as will be seen later. Taking into account this crystallographic description a $\mathrm{Ca}^{2+}$ cation is surrounded by four first-neighbours $\mathrm{Zn}^{2+}$ ions with $\mathrm{Ca}-\mathrm{Zn}$ distances of about $2.35 \AA$ and six second-neighbours $\mathrm{S}^{2-}$ anions with $\mathrm{Ca}$-S distances of about $2.7 \AA$ in agreement with $\mathrm{Ca}^{2+}$ environmental description in CaS rock-salt CaS structure [25]. Due to steric hindrance the exclusion of four $\mathrm{Zn}^{2+}$ ions present in the first $\mathrm{Ca}^{2+}$ coordination shell, three of them located in faces center and the last one located at the top of the cubic cell, leads actually to the disappearance of $1.625 \mathrm{Zn}^{2+}$ ions for one $\mathrm{Ca}^{2+}$ ion, due to the fact that $\mathrm{Zn}^{2+}$ ions are shared between adjacent cells. These new zinc vacancies are due to the $\mathrm{Ca}^{2+}$ doping and are likely to be added to those already existing in the blende framework.

Particle sizes were calculated for each sample using the Scherrer formula [26]:

$$
D=\frac{0.9 \lambda}{\beta \cos \theta}
$$


where $\mathrm{D}$ is the average particle size, $\lambda$ is the $\mathrm{X}$-ray wavelength, $\beta$ is the full width at half maximum (FWHM) and $\theta$ is the diffraction angle value. The average particle size calculated, considering all (111), (220) and (311) diffraction planes, slowly increases according to the increase of $\mathrm{Ca}^{2+}$ content until a doping value of $3 \mathrm{~mol} \%$ (see Table 1). Higher doping contents are characterized by a small decrease of the crystallite size. Grain size of nanometric scale was expected taking into account the operating protocol used.

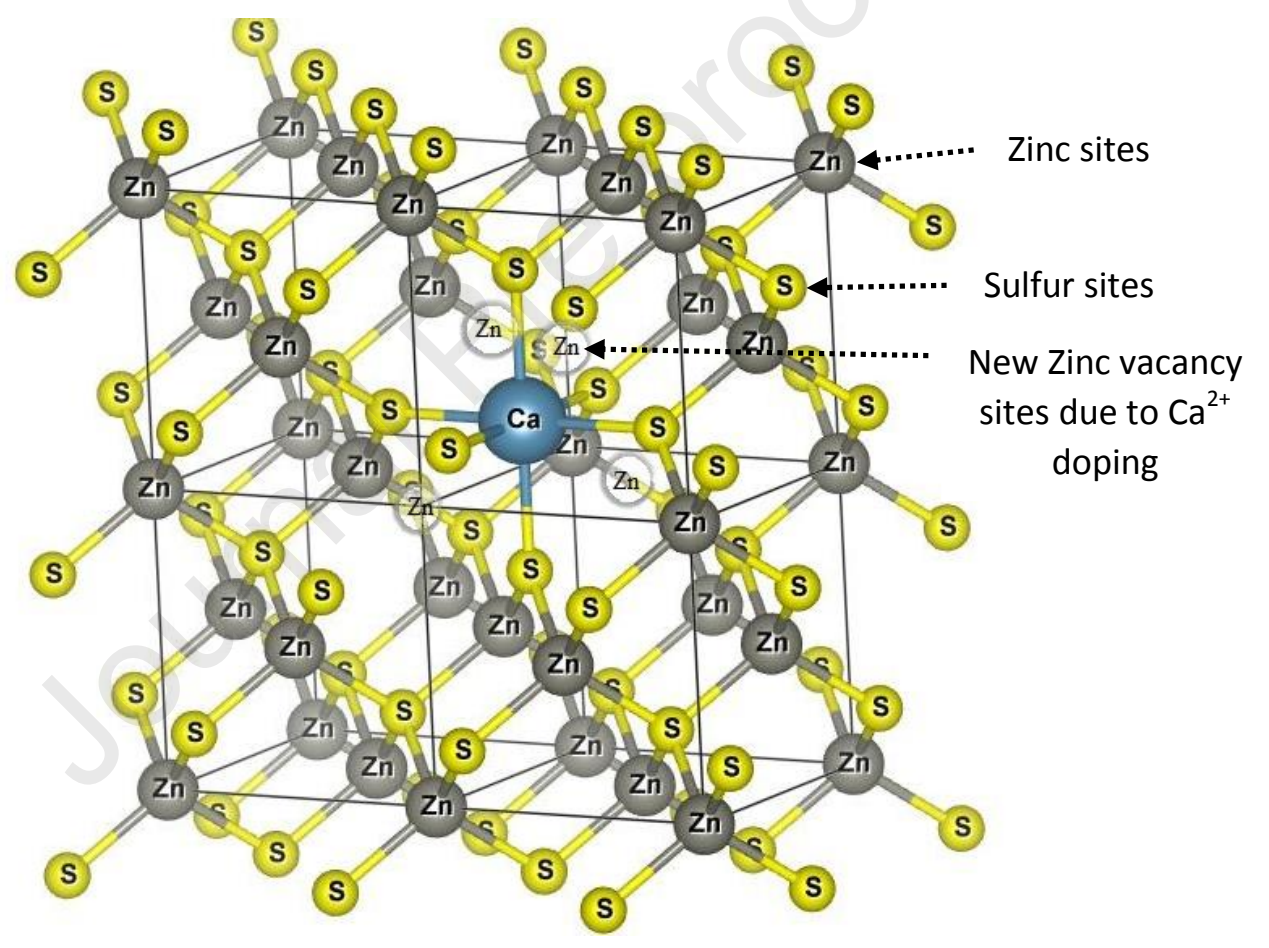

Fig. 2 Crystal structure of ZnS: Ca blende polymorph.

The average lattice constants values were calculated on the basis of the main three (111), (220) and (311) diffraction peaks using the following formula [26]:

$$
d_{h k l}=\frac{a}{\sqrt{h^{2}+k^{2}+l^{2}}}
$$


where $h, k$ and $l$ are the Miller indices of the considered Bragg planes. They are gathered in Table 1.

The lattice parameters do not significantly change considering $\mathrm{Ca}^{2+}$ doping amounts which provides another proof to the fact that the invited ions are not substituted for $\mathrm{Zn}^{2+}$ ones but are located into interstitial sites as shown in Fig. 2.

Table 1 Particle sizes and lattice parameters for $\mathrm{ZnS}$ and $\mathrm{ZnS}$ : $\mathrm{x} \% \mathrm{Ca}$ NPs.

\begin{tabular}{|c|c|c|}
\hline Sample & Particles size $(\mathrm{nm})$ & Lattice parameter $(\AA)$ \\
\hline $\mathrm{ZnS}$ & $6.6(1)$ & $5.379(2)$ \\
\hline $\mathrm{ZnS}: 1.5 \% \mathrm{Ca}$ & $6.9(1)$ & $5.380(2)$ \\
\hline $\mathrm{ZnS}: 3 \% \mathrm{Ca}$ & $8.3(1)$ & $5.396(2)$ \\
\hline $\mathrm{ZnS}: 4.5 \% \mathrm{Ca}$ & $6.0(1)$ & $5.381(2)$ \\
\hline $\mathrm{ZnS}: 6 \% \mathrm{Ca}$ & $6.2(1)$ & $5.379(2)$ \\
\hline
\end{tabular}

\subsection{SEM and TEM analysis}

SEM images of undoped and $\mathrm{Ca}^{2+}$ doped $\mathrm{ZnS}(\mathrm{x}=6 \mathrm{~mol} \%)$ are shown in Fig. 3(A). Nanoparticles of undoped and $\mathrm{Ca}^{2+}$ doped $\mathrm{ZnS}$ materials show a microsphere structure with diameters comprised from $800 \mathrm{~nm}$ to $2 \mu \mathrm{m}$, which is constructed by nanoparticles self-assembly. These marbles show a smooth surface without any appreciable roughness. All morphologies are similar whatever the doping ion amount in the range 0-6\% Ca. 
Fig. 3(B) show the TEM images of undoped and $\mathrm{Ca}^{2+}$ doped $\mathrm{ZnS}$ NPs $(\mathrm{x}=6 \mathrm{~mol} \%)$. These micrographs confirm the spherical shape of nanoparticles with size distribution comprised in the range 40-140 $\mathrm{nm}$. TEM images corroborate thus that nanoparticles are consistent with isotropically assembled crystallites which mean size was determined by Scherrer law.

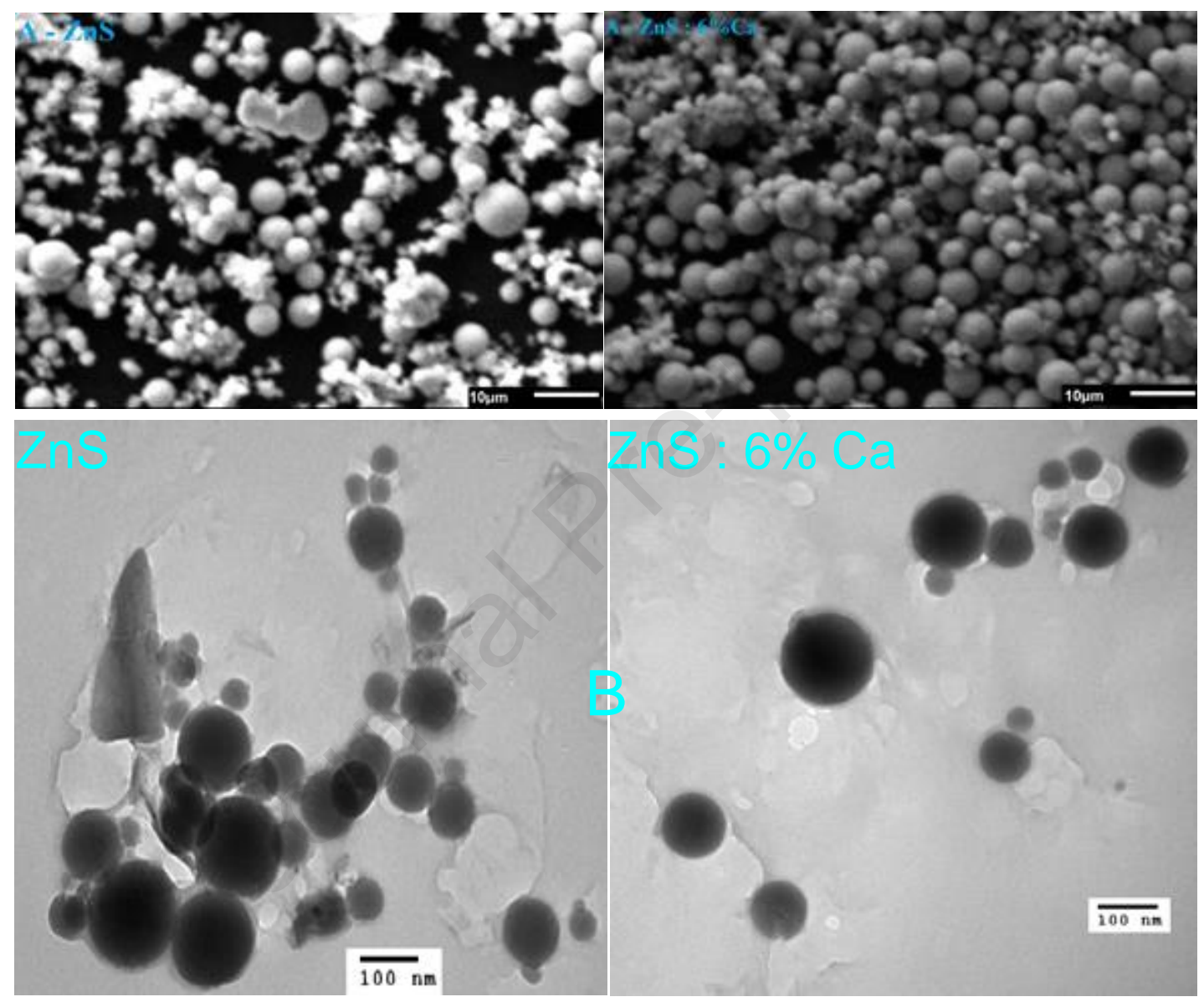

Fig. 3 (A) Scanning electron microscopy (SEM) images of ZnS and ZnS: 6 mol \% Ca.

(B) Transmission electron microscopy (TEM) images of ZnS and ZnS: 6 mol \% Ca.

\subsection{Raman scattering}

Raman scattering is an inelastic and a non-destructive process to obtain vibrational states information for a solid material. The Raman spectra were recorded at room temperature in order to obtain more detailed structural information of ZnS: Ca x\% NPs. Spectra of undoped and $\mathrm{Ca}^{2+}$ 
doped ZnS samples are reported in Fig. 4. Two characteristic peaks located at 260 and $350 \mathrm{~cm}^{-1}$ are well observed. These results are similar to those found by Mou Pal et al [27].

The small peak at $260 \mathrm{~cm}^{-1}$ can be attributed to the first-order transverse optical mode whereas the relatively intense and broad peak appearing at $350 \mathrm{~cm}^{-1}$ is attributed to the first-order longitudinal optical mode of cubic $\mathrm{ZnS}$ [28]. No extra bands are observed indicating again the validity of the synthesis protocol.

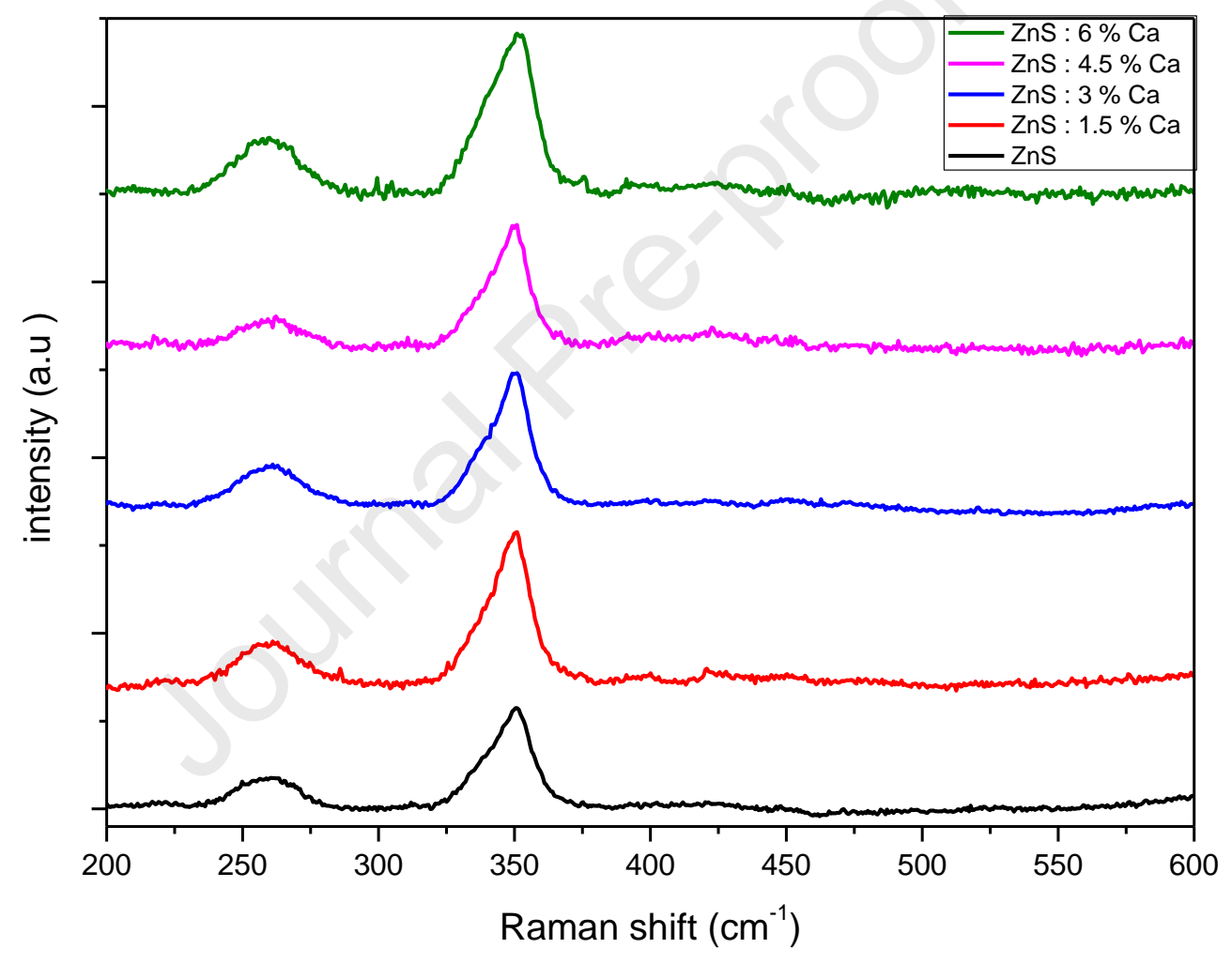

Fig. 4 Raman spectra of $\mathrm{ZnS}$ and $\mathrm{ZnS}$ : $\mathrm{x} \%$ Ca NPs.

\subsection{Optical properties}

The PL-QYs plotted versus the excitation wavelength for undoped and $\mathrm{Ca}^{2+}$ doped $\mathrm{ZnS}$ are presented in Fig. 5. Overall emission lying between 400 and $650 \mathrm{~nm}$ was integrated. The 
internal quantum yields obtained at room temperature under a $400 \mathrm{~nm}\left(25000 \mathrm{~cm}^{-1}\right)$ excitation are gathered in Table 2.

The excitation PL-QY spectra of all samples show a unique dissymmetric broad band peaking at $25000 \mathrm{~cm}^{-1}(400 \mathrm{~nm})$ wavelength excitation. The undoped ZnS NPs present an internal QY of $4.7 \%$, the highest value $(8.4 \%)$ was obtained for $\mathrm{ZnS}: 3 \% \mathrm{Ca}$, which exhibits the largest crystalline size. Therefore, $\mathrm{Ca}^{2+}$ ions doping improves the PL-QYs of ZnS NPs.

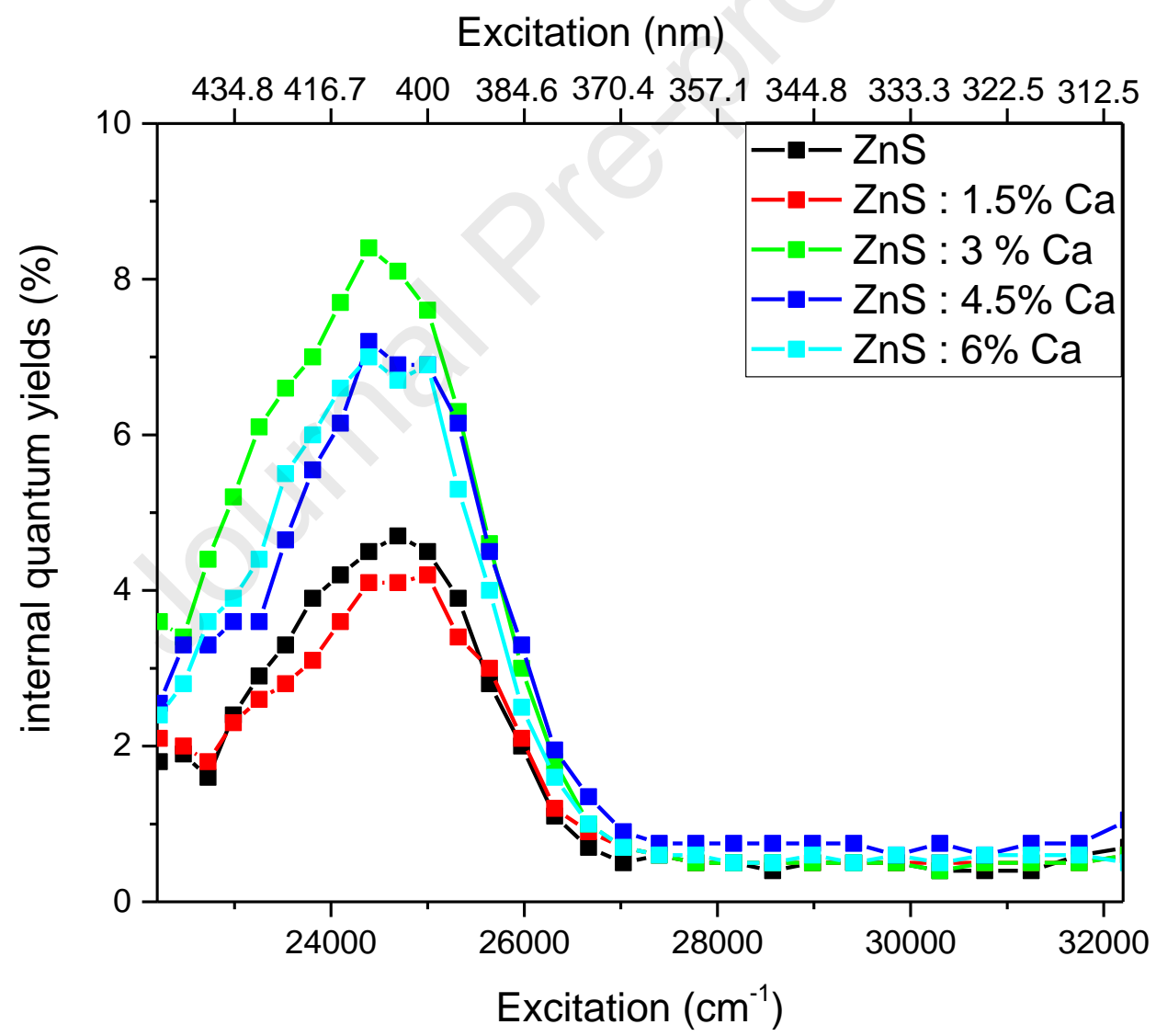

Fig. 5 Internal quantum yield of $\mathrm{ZnS}$ and $\mathrm{ZnS}: \mathrm{x} \% \mathrm{Ca}$. 
The excitation and emission spectra were recorded at room temperature in the same conditions for all samples. Fig. 6 shows the normalized photoluminescence excitation (PLE) spectra of ZnS: $\mathrm{x} \%$ Ca phosphors (with $\mathrm{x}=0-6 \mathrm{~mol} \%$ ) monitoring an emission wavelength of $\lambda_{\mathrm{em}}=16129 \mathrm{~cm}^{-1}(620 \mathrm{~nm})$ corresponding to the red emission band edge for avoiding excitation beam scattering. The excitation spectra were recorded from $20000(500 \mathrm{~nm})$ to 30000 (333 $\mathrm{nm}) \mathrm{cm}^{-1}$. All excitation spectra were corrected from the spectral response of the apparatus and are characterized by a unique broad band, centered at $25000 \mathrm{~cm}^{-1}(400 \mathrm{~nm})$, which corresponds perfectly to the energy gap of this semiconductor. This result is in agreement with the PL-QY reported in Fig. 5. Moreover, no shift due to the $\mathrm{Ca}^{2+}$ ions doping is noticed.

Table 2 Internal quantum efficiencies for $\mathrm{ZnS}$ and $\mathrm{ZnS}$ : x\% Ca NPs under $400 \mathrm{~nm}$ excitation.

\begin{tabular}{|c|c|}
\hline Sample & Internal Quantum Yield \\
& $(\%)$ \\
\hline $\mathrm{ZnS}$ & 4.7 \\
\hline $\mathrm{ZnS}: 1.5 \% \mathrm{Ca}$ & 4.2 \\
\hline $\mathrm{ZnS}: 3 \% \mathrm{Ca}$ & 8.4 \\
\hline $\mathrm{ZnS}: 4.5 \% \mathrm{Ca}$ & 7.2 \\
\hline $\mathrm{ZnS}: 6 \% \mathrm{Ca}$ & 7.0 \\
\hline
\end{tabular}

The photoluminescence (PL) emission spectra shown in Fig. 7 were recorded from 16000 $\mathrm{cm}^{-1}$ to $24000 \mathrm{~cm}^{-1}$ under excitation at $25000 \mathrm{~cm}^{-1}(400 \mathrm{~nm})$ using the OPO laser for all undoped and $\mathrm{Ca}^{2+}$ doped samples. A wide emission band centered at $19048 \mathrm{~cm}^{-1}(525 \mathrm{~nm})$ is observed 
whatever the doping ion amounts, the intensity of which varies very little as a function of doping rate.

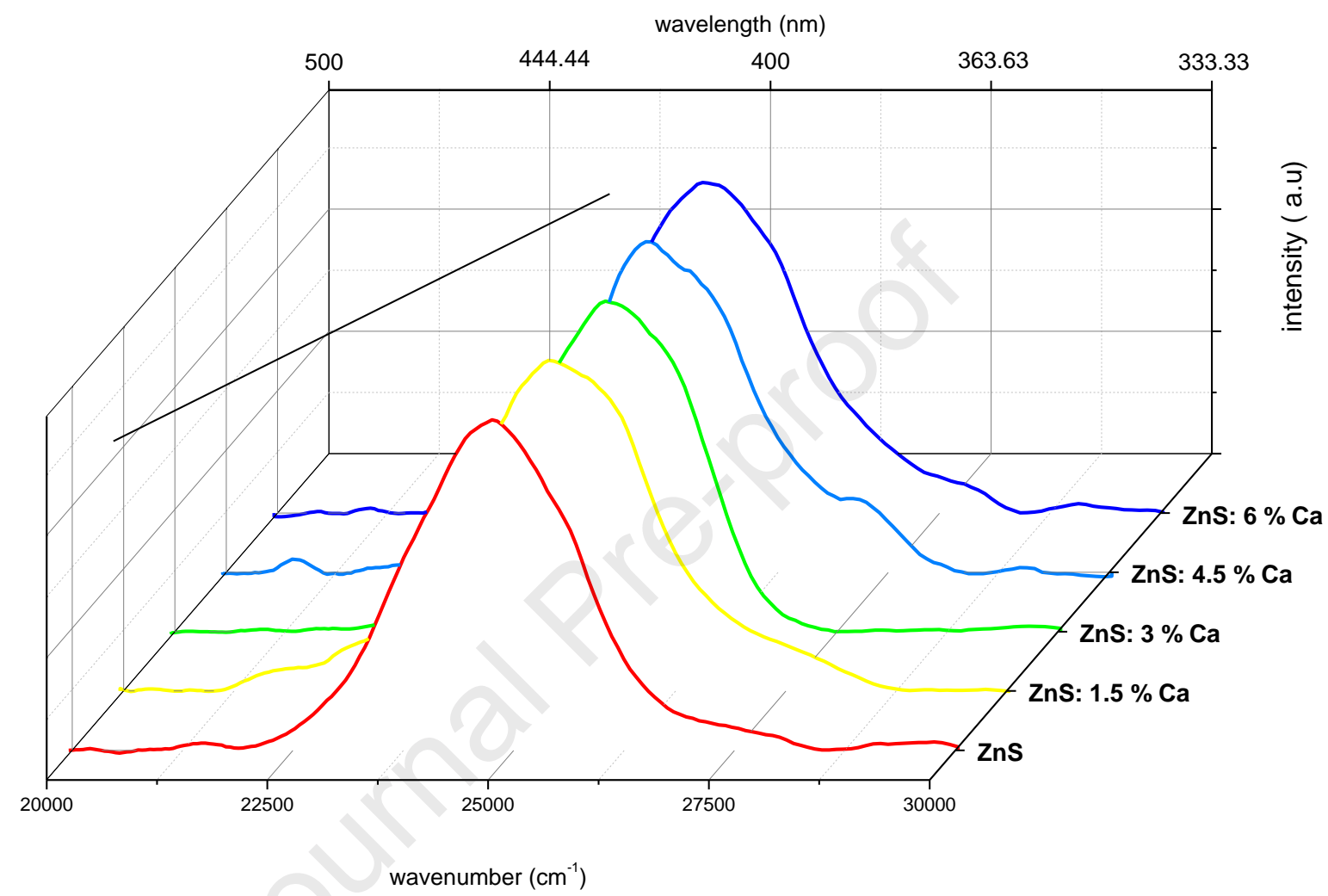

Fig. 6 Photoluminescence excitation spectra $\left(\lambda_{\text {em }}=16129 \mathrm{~cm}^{-1}-620 \mathrm{~nm}\right)$ of $\mathrm{ZnS}$ and $\mathrm{ZnS}: \mathrm{x} \% \mathrm{Ca}$.

Nanocrystals have a very high surface-to-volume ratio due to their very small diameter, which makes them vulnerable to various surface defects. The origin of luminescence was studied by different groups for the undoped $\mathrm{ZnS}$ and $\mathrm{ZnS}$ doped nanocrystals [2,14,15,27,29-36]. They have demonstrated that the photoluminescence effect is attributed to intrinsic defects due to crystal lattice vacancies such as sulphur and zinc vacancies given that $\mathrm{Zn}^{2+}$ and $\mathrm{S}^{2-}$ ions are not 
luminescent. Besides part of the fluorescence emission is due to introduced dopant ions such as $\mathrm{Eu}^{3+}[27], \mathrm{Mn}^{2+}[29,31,33]$ or $\mathrm{Cu}$ moieties [32].

In our work $\mathrm{ZnS}$ and $\mathrm{ZnS}$ : $\mathrm{Ca}$ show an emission covering the whole visible region. $\mathrm{Ca}^{2+}$ is an alkaline-earth ion and thus does not show luminescence properties but its effect as impurity in semiconductor materials would obviously affect emission intensity according to the presented experimental results. The emission band surface area for each sample was calculated for comparison. The results are gathered in Table 3. Thus, the fluorescence efficiencies of $\mathrm{ZnS}: \mathrm{Ca}$ samples are higher than that of undoped $\mathrm{ZnS}$ samples. $\mathrm{Ca}^{2+}$ ions doped samples exhibit PL emission intensity approximately twice as high as that of non-doped sample. Besides the fluorescence intensity observed for the different doped samples is almost similar. The calculation of the full-width at half maximum (FWHM) of fluorescence intensity shows that the $\mathrm{ZnS}: 3 \%$ sample has the widest spectral range compared to other samples.

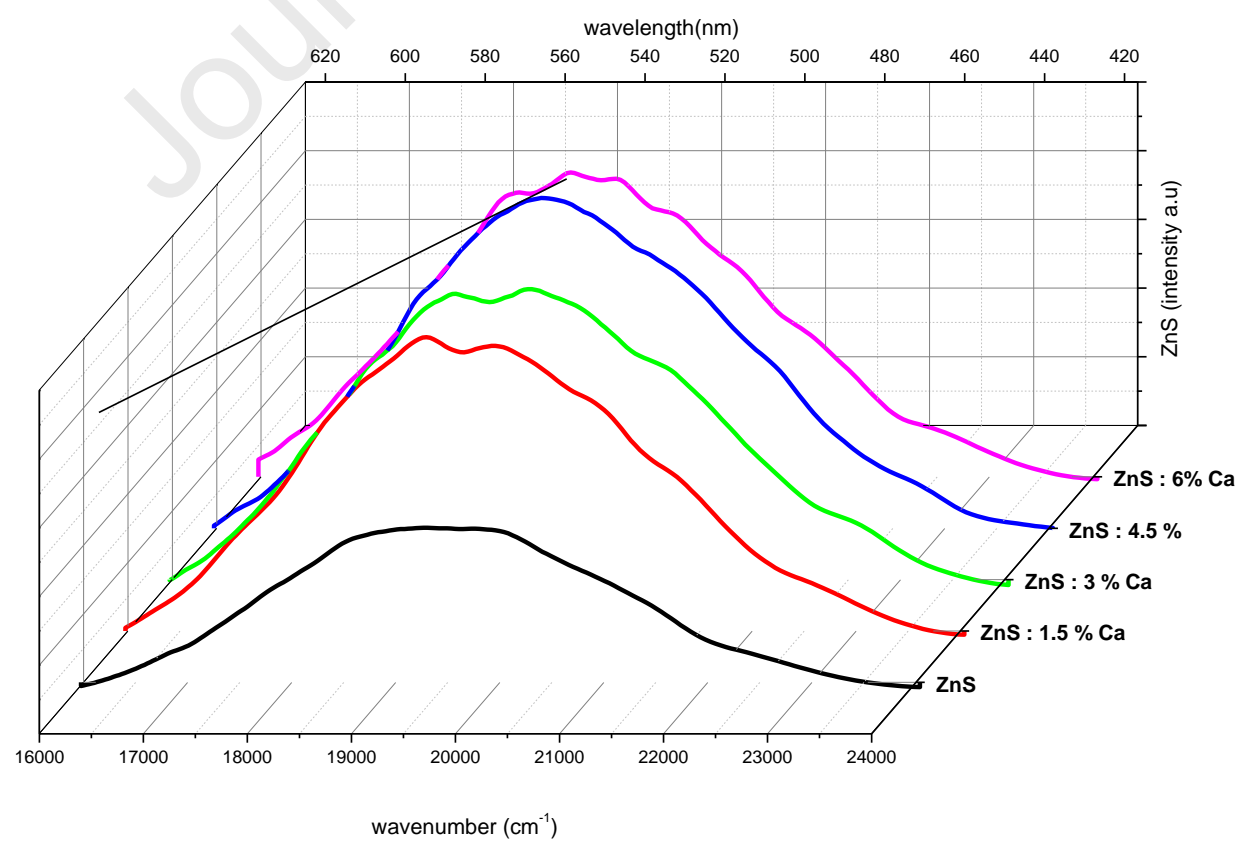

Fig. 7 Photoluminescence emission spectra of $\mathrm{ZnS}$ and $\mathrm{ZnS}: \mathrm{x} \% \mathrm{Ca}$ NPs $\left(\lambda_{\mathrm{exc}}=400 \mathrm{~nm}\right)$. 
It is observed from Fig. 7 that the emission bands are highly asymmetric and broadened especially at higher wavelength side, indicating that different luminescence centers are involved in radiative processes. A deconvolution of the luminescence band response using a Gaussian law was conducted in order to better understand the emission phenomena. The Gaussian deconvolution of the broad PL emissions for undoped $\mathrm{ZnS}$ and $3 \% \mathrm{Ca}^{2+}$ doped phosphors are presented in Figure 8.

The undoped $\mathrm{ZnS}$ emission spectra deconvolution (Fig. 8-A) shows the presence of two bands. The band located at $20660 \mathrm{~cm}^{-1}(484 \mathrm{~nm})$ is attributed to the emission transition of intrinsic defects due to sulfur vacancies $\left(V_{S}\right)$, whereas the most intense band at around $18762 \mathrm{~cm}^{-}$ ${ }^{1}(533 \mathrm{~nm})$ is due to the emission transition of intrinsic defects specific to zinc vacancies $\left(\mathrm{V}_{\mathrm{Zn}}\right)$ [23].

Table 3 Area of PL emission spectra.

\begin{tabular}{|c|c|}
\hline Sample & Area of \\
& photoluminescence \\
& emission spectra (a.u.) \\
\hline $\mathrm{ZnS}$ & 0.49 \\
\hline $\mathrm{ZnS}: 1.5 \% \mathrm{Ca}$ & 0.90 \\
\hline $\mathrm{ZnS}: 3 \% \mathrm{Ca}$ & 0.96 \\
\hline $\mathrm{ZnS}: 4.5 \% \mathrm{Ca}$ & 1 \\
\hline $\mathrm{ZnS}: 6 \% \mathrm{Ca}$ & 0.90 \\
\hline
\end{tabular}


The intensity of the band corresponding to intrinsic defects linked to $\mathrm{V}_{\mathrm{Zn}}$ vacancies is higher than that due to intrinsic defects specific of $\mathrm{V}_{\mathrm{S}}$ vacancies which is probably due to the fact that the samples synthesis was operated taking into account a $1 / 2$ ratio for $\mathrm{Zn} / \mathrm{S}$ precursors implying an excessive amount of sulphur. This certainly implies the presence of much more $\mathrm{Zn}$ vacancies in the undoped zinc sulfide phosphor than $S$ vacancies. Similar results have been reported by Wei et al. [23] who noticed that the difference in intensity between both characteristic transitions varies according to the ratio between the precursor amounts in their hydrothermal protocol.
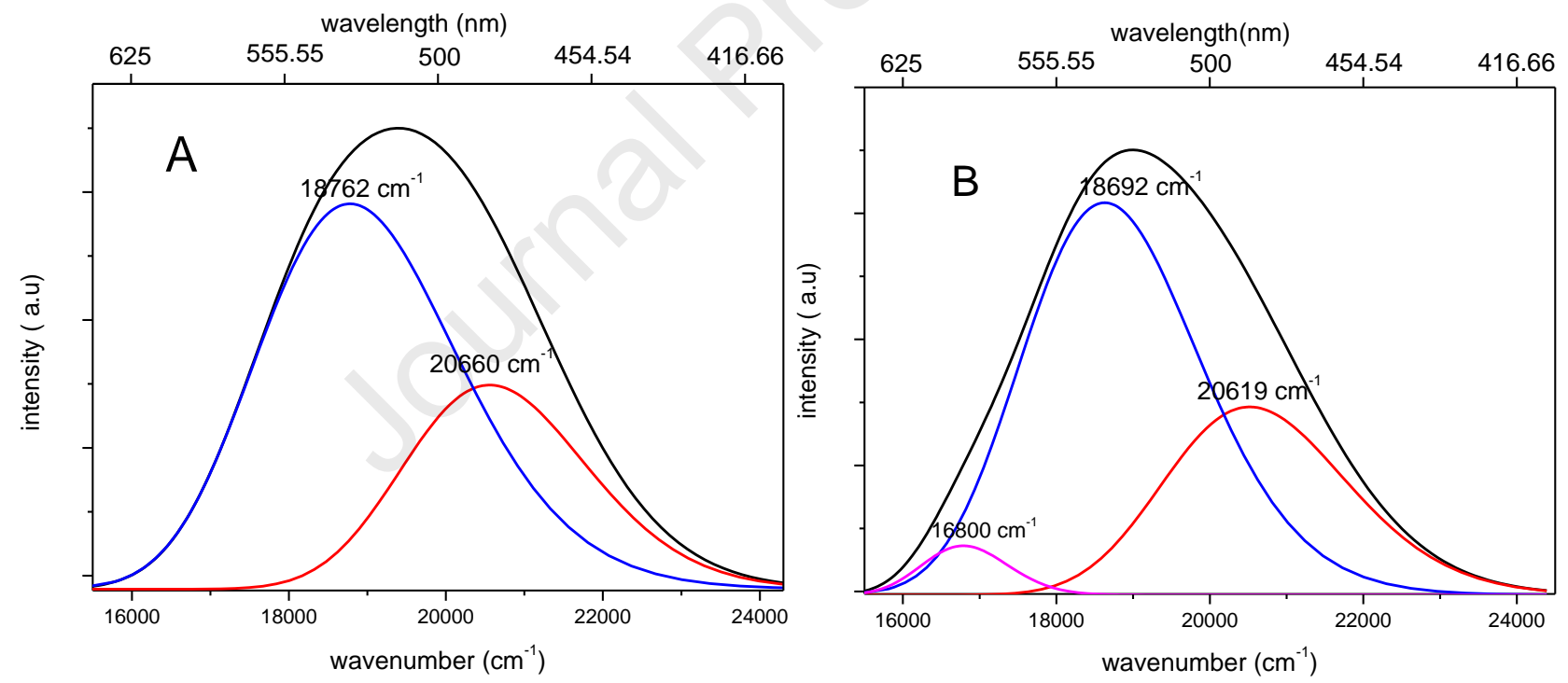

Fig. 8 Gaussian deconvolution of experimental PL emission of (A) undoped ZnS and (B) $\mathrm{ZnS}: 3 \% \mathrm{Ca}\left(\lambda_{\mathrm{exc}}=400 \mathrm{~nm}\right)$.

The deconvolution of $\mathrm{ZnS}: 3 \% \mathrm{Ca}$ (figure 8-B) emission spectrum exhibits the presence of three bands. The first two bands located near $20619 \mathrm{~cm}^{-1}(485 \mathrm{~nm})$ and $18692 \mathrm{~cm}^{-1}(535 \mathrm{~nm})$ 
are similar to that observed for undoped $\mathrm{ZnS}$ samples. A slight shift of wavelengths values is however observed for the $3 \%$ Ca doped sample compared to the undoped one. The third band appearing near $16807 \mathrm{~cm}^{-1}(595 \mathrm{~nm})$ with a very weak intensity is attributed to $\mathrm{Ca}^{2+}$ impurity incorporated in $4 \mathrm{~d}$ sites, which create new energy levels between the valence band and the conduction band as previously reported in the literature [14,17,33]. The Gaussian plot was conducted for all $\mathrm{Ca}^{2+}$ doped samples emission bands, the $16807 \mathrm{~cm}^{-1}(595 \mathrm{~nm})$ band intensity being similar from one sample to another. However, the $\mathrm{Ca}^{2+}$ ion contribution is felt on the overall band intensity as shown in Fig. 7 .

Although best quantum yields are obtained under excitation at $400 \mathrm{~nm}$ (as shown in Fig.5), different emission spectra for the undoped $\mathrm{ZnS}$ sample and for the highly doped one $(\mathrm{ZnS}: 6 \% \mathrm{Ca})$ were recorded under different excitation wavelenghts as $280,300,330$ and 360 nm. These PL emission spectra are shown in Fig 9. The emission spectrum recorded under a 400 $\mathrm{nm}$ excitation wavelength was reported for comparison. The same features are observed in both figures. A slight red shift is observed depending on the excitation wavelength for a given sample. Moreover a very slight red shift (approximatively $2 \mathrm{~nm}$ ) is observed for the $6 \%$ Ca doped sample for a given excitation wavelength. This was observed in deconvolutions reported in Fig.8. Under excitation at 280 and $300 \mathrm{~nm}$, the emission band is centered near $480 \mathrm{~nm}$ and shoulders are recorded near 400 and $430 \mathrm{~nm}$. Under excitation at 330 and $360 \mathrm{~nm}$, the band is shifted towards $500 \mathrm{~nm}\left(\lambda_{\mathrm{exc}}=330 \mathrm{~nm}\right)$ and $505 \mathrm{~nm}\left(\lambda_{\mathrm{exc}}=360 \mathrm{~nm}\right)$. Moreover relatively intense components are recorded near 395,415 and $440 \mathrm{~nm}$. With $\lambda_{\text {exc }}=400 \mathrm{~nm}$, the main band is observed near $523 \mathrm{~nm}$ for undoped $\mathrm{ZnS}$ and $525 \mathrm{~nm}$ for $\mathrm{ZnS} \mathrm{:} \mathrm{6 \%} \mathrm{Ca} \mathrm{without} \mathrm{any} \mathrm{visible} \mathrm{shoulders.}$ 
These optical features are certainly linked to the presence of impurities originating from raw materials used for NP syntheses especially zinc acetate dihydrate. As evidenced by Saleh $e t$ al [37] during investigation on undoped commercial $\mathrm{ZnS}$ several impurities are detected which are responsible for their own emission band features. Emission bands corresponding to Ag are observed near 400 and $450 \mathrm{~nm}$. Cu impurities give emission bands in the blue region near $420 \mathrm{~nm}$ and in the green domain near $520 \mathrm{~nm}$. Band recorded near 470-480 $\mathrm{nm}$ correspond to a donoracceptor pair emission for which isolated $\mathrm{Cl}^{-}$or $\mathrm{Al}^{3+}$ ions act as donors and $\mathrm{Zn}$ vacancies- $\mathrm{Cl}^{-}$(or $\mathrm{Al}^{3+}$ ) pairs act as acceptors. Saleh et al highlighted the following impurities amount: 0.39 ppm for $\mathrm{Cu}$, about $0.03 \mathrm{ppm}$ for $\mathrm{Ag}$ and $1.5 \mathrm{ppm}$ for Al. As evidenced by Sigma-Aldrich data sheet analysis for zinc acetate dihydrate, amounts of chlorine contaminant is about $5 \mathrm{ppm}$. No evidence of $\mathrm{Cu}, \mathrm{Ag}$ and $\mathrm{Al}$ is given in the analysis sheet probably due to their very low amount. However presence of copper is not excluded due to similar atomic mass. $\mathrm{Cu}$ contaminant probably comes from the $\mathrm{Zn}$ source. Other elements such as iron and lead are analysed as contaminants (5 ppm for $\mathrm{Fe}$ and $20 \mathrm{ppm}$ for $\mathrm{Pb}$ ). However it is difficult to detect $\mathrm{Pb}$ impurities in our samples since $\mathrm{ZnS}: \mathrm{Pb}$ phosphors are characterized by a broad band centered near $580 \mathrm{~nm}$ under a $363 \mathrm{~nm}$ excitation [38]. The role of contaminants in our samples needs more precise investigations. This will be carried out in further works. 

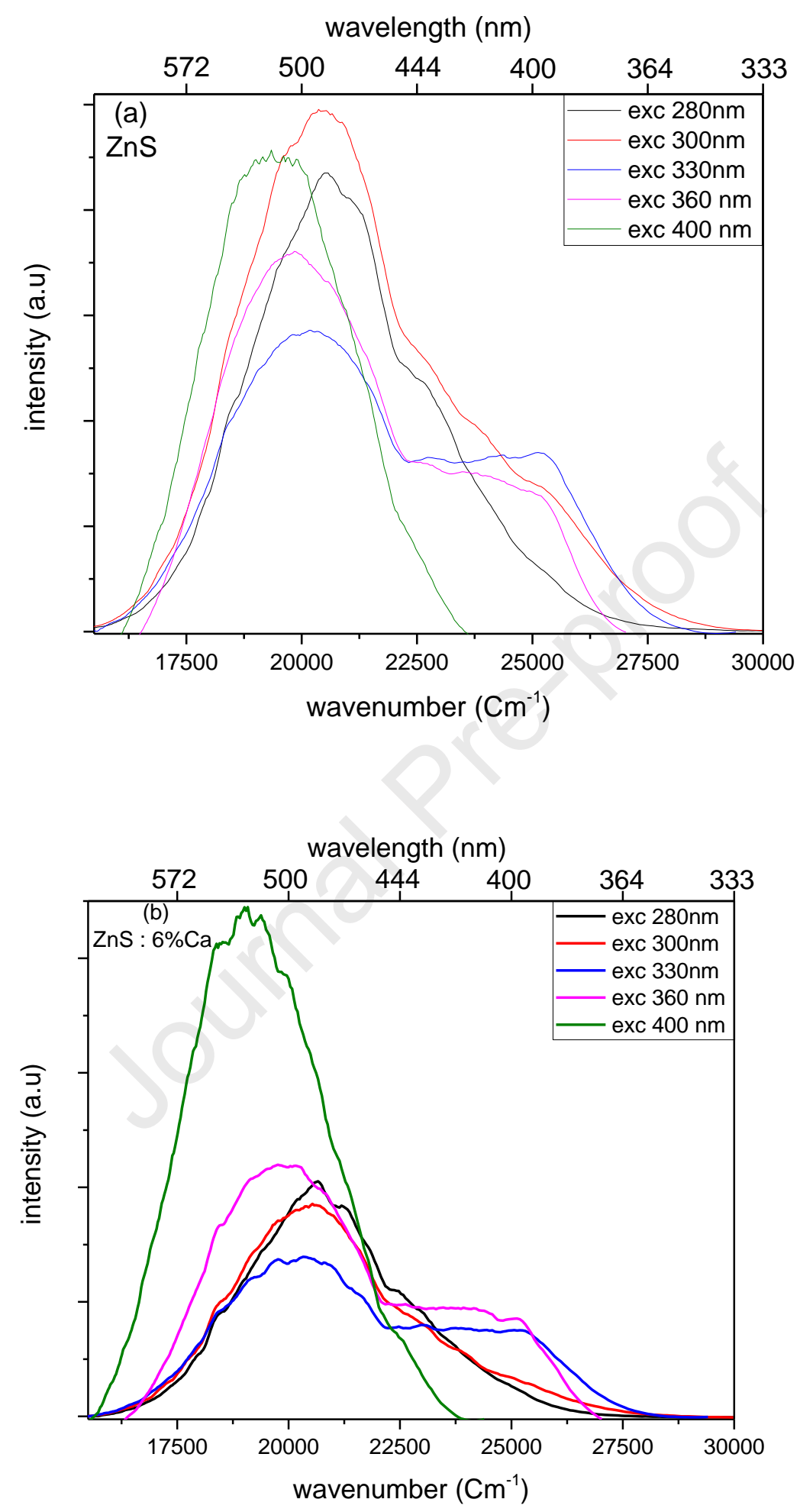

Fig. 9 Photoluminescence emission spectra of undoped ZnS (a) and ZnS: $6 \%$ Ca (b) NPs under different excitation wavelengths. 
The decay curves recorded for each $\mathrm{ZnS}: \mathrm{x} \%$ Ca sample $(\mathrm{x}=0 ; 1.5 ; 3 ; 4.5$ and 6$)$ under excitation at $25000 \mathrm{~cm}^{-1}(400 \mathrm{~nm})$, monitoring the emission at its maximum located at $19048 \mathrm{~cm}^{-}$ ${ }^{1}(525 \mathrm{~nm})$ are reported in Fig. 10.

As observed in Fig. 10 all the decays diverge from single exponential shape. In order to estimate the PL decay times, the photoluminescence decay curves were fitted assuming a biexponential law given by the following equation [39]:

$$
I(t)=C+A_{1} e^{-t / \tau_{1}}+A_{2} e^{-t / \tau_{2}}
$$

where $A_{1}$ and $A_{2}$ are the amplitudes of each decay component, $\tau_{1}$ and $\tau_{2}$ are the decay times. $\mathrm{I}(\mathrm{t})$ is the luminescence intensity at time $\mathrm{t}$ and $\mathrm{C}$ a constant. The calculated results are gathered in Table 4.

As observed from the Gaussian deconvolution (see Fig. 8), the emission band covers two main components due to zinc and sulphur vacancies, with respective emissions peaking at 18692 $\mathrm{cm}^{-1}(535 \mathrm{~nm})$ and $20619 \mathrm{~cm}^{-1}(485 \mathrm{~nm})$ wavenumbers (wavelengths). According to Wei et al [23] a lifetime value increase is correlated to an increase of the intrinsic defects amount. Taking into account the synthesis protocol intrinsic defects due to $\mathrm{Zn}$ vacancies are supposed to be prominent, thus $\tau_{2}$ time constant values corresponding to the band located at $18692 \mathrm{~cm}^{-1}$ (535 nm) are higher than $\tau_{1}$ lifetime values corresponding to the band located at $20619 \mathrm{~cm}^{-1}$ (485 nm). As discussed in the crystallographic section (3.1) a $\mathrm{Ca}^{2+}$ doping results in an increase of intrinsic defects linked to $\mathrm{Zn}$ vacancies. Therefore this implies an increase of $\tau_{2}$ lifetime values for $\mathrm{Ca}^{2+}$ doped materials in comparison with undoped one. However $\tau_{1}$ lifetime values are weakly influenced by the $\mathrm{Ca}$ doping due to the synthesis protocol. $\tau_{1}$ and $\tau_{2}$ lifetime values are independent of $\mathrm{Ca}^{2+}$ doping amounts. Such observation can be connected to a lack of structural 
defects other than those related to zinc and sulphur vacancies or chemical impurities. Attempts of PL decay curves fitting with a tri-exponential formula taking into account the third emission band due to $\mathrm{Ca}^{2+}$ impurities do not lead to operable results which is probably due to the very weak intensity of the corresponding emission band located near $16807 \mathrm{~cm}^{-1}(595 \mathrm{~nm})$.

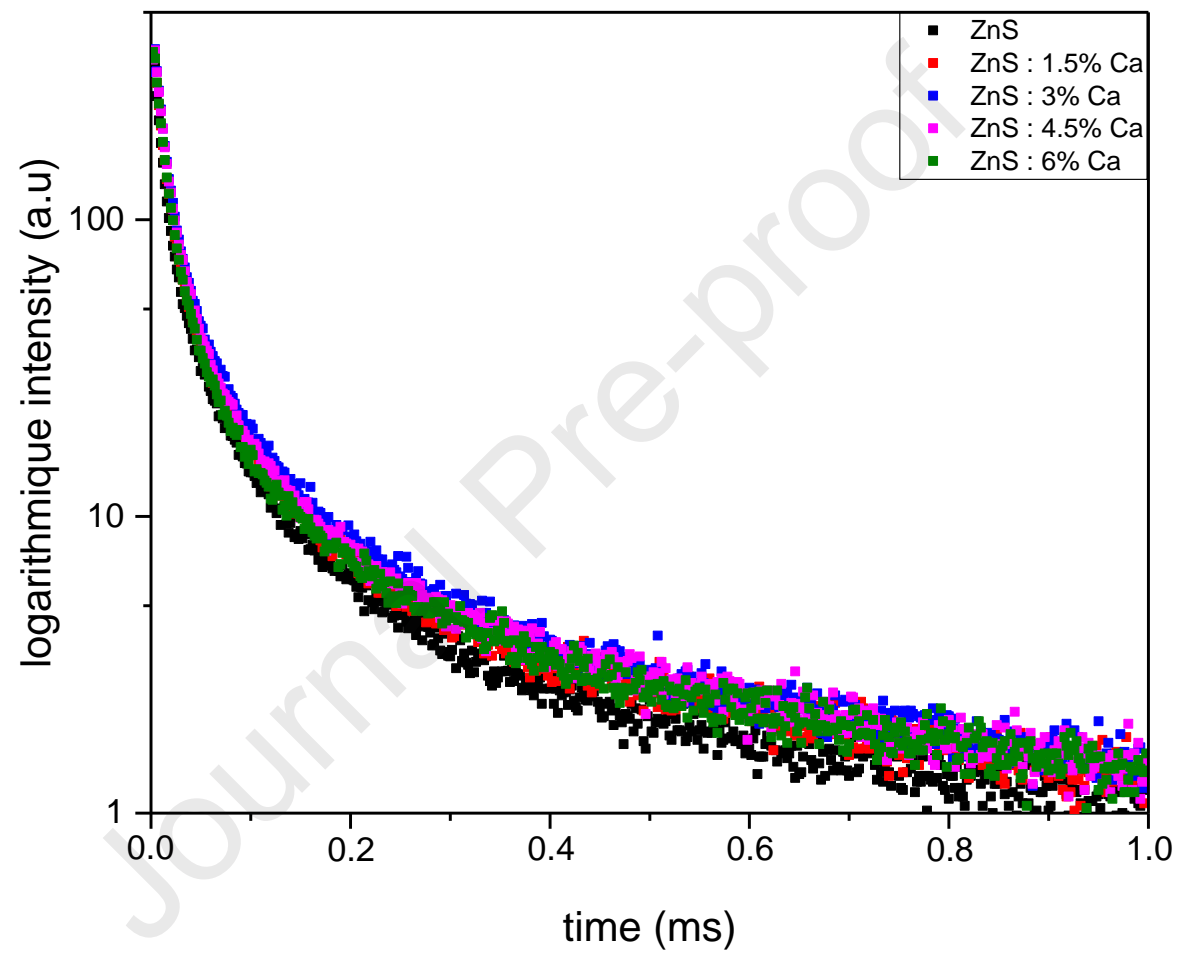

Fig. 10 Photoluminescence decay curves recorded for $\mathrm{ZnS}$ and $\mathrm{ZnS}$ : $\mathrm{x} \% \mathrm{Ca}$ NPs samples at $19048 \mathrm{~cm}^{-1}$ under excitation at $25000 \mathrm{~cm}^{-1}(400 \mathrm{~nm})$. 
Table 4 Lifetime values for $\mathrm{ZnS}$ and $\mathrm{ZnS}: \mathrm{x} \%$ Ca NPs $\left(\lambda_{\mathrm{exc}}=400 \mathrm{~nm}\right)$.

\begin{tabular}{|c|c|c|c|c|}
\hline Sample & $\tau_{1}(\mu \mathrm{s})$ & $\mathrm{A}_{1}$ (a.u) & $\tau_{2}(\mu \mathrm{s})$ & $\mathrm{A}_{2}$ (a.u) \\
\hline $\mathrm{ZnS}$ & 11.4 & 387 & 83.4 & 43 \\
\hline $\mathrm{ZnS}: 1.5 \% \mathrm{Ca}$ & 12.7 & 576 & 90.7 & 43 \\
\hline $\mathrm{ZnS}: 3 \% \mathrm{Ca}$ & 14.4 & 374 & 105.8 & 45 \\
\hline $\mathrm{ZnS}: 4.5 \% \mathrm{Ca}$ & 15.3 & 352 & 105.4 & 40 \\
\hline $\mathrm{ZnS}: 6 \% \mathrm{Ca}$ & 14.6 & 341 & 108.1 & 34 \\
\hline
\end{tabular}

Moreover decay curves were recorded for each excitation wavelength $\left(\lambda_{\text {exc }}=280,300\right.$, 330, $360 \mathrm{~nm}$, see Fig.9) monitoring the main band emission. These experimental decays are well fitted by a bi-exponential law. $\mathrm{A}_{1}-\mathrm{A}_{2}$ amplitude and $\tau_{1}-\tau_{2}$ decay time values are gathered in Table 5. Typical values calculated under a $400 \mathrm{~nm}$ excitation wavelength are indicated for comparison. For excitation wavelengths lower than $400 \mathrm{~nm}, \tau_{1}$ and $\tau_{2}$ lifetime values are slightly higher than values calculated for the $400 \mathrm{~nm}$ excitation and are not influenced by the excitation wavelength value. The longer $\tau_{1}$ and $\tau_{2}$ lifetime values are probably due to the influence of optically active impurities whose characteristic emission features are superimposed with that of $\mathrm{ZnS}$ undoped and doped samples. 


\begin{tabular}{|c|c|c|c|c|}
\hline \multicolumn{5}{|c|}{$\mathrm{ZnS}$} \\
\hline$\lambda_{\text {exc }}(\mathrm{nm})$ & $\tau_{1}(\mu \mathrm{s})$ & $\mathrm{A}_{1}(\mathrm{a} . \mathrm{u})$ & $\tau_{2}(\mu \mathrm{s})$ & $\mathrm{A}_{2}(\mathrm{a} . \mathrm{u})$ \\
\hline 280 & 22.7 & 10829 & 110.4 & 811 \\
\hline 300 & 25.1 & 8718 & 113.5 & 1527 \\
\hline 330 & 20.1 & 6358 & 105.8 & 565 \\
\hline 360 & 23.6 & 7994 & 131.9 & 535 \\
\hline 400 & 11.4 & 387 & 83.4 & 43 \\
\hline
\end{tabular}

\begin{tabular}{|c|c|c|c|c|}
\hline \multicolumn{5}{|c|}{$\mathrm{ZnS}: 6 \% \mathrm{Ca}$} \\
\hline$\lambda_{\text {exc }}(\mathrm{nm})$ & $\tau_{1}(\mu \mathrm{s})$ & $\mathrm{A}_{1}($ a.u $)$ & $\tau_{2}(\mu \mathrm{s})$ & $\mathrm{A}_{2}($ a.u $)$ \\
\hline 280 & 23.0 & 11247 & 113.7 & 977 \\
\hline 300 & 22.6 & 8730 & 107.6 & 1024 \\
\hline 330 & 21.0 & 6457 & 110.4 & 501 \\
\hline 360 & 23.9 & 9659 & 130.0 & 700 \\
\hline 400 & 14.6 & 341 & 108.1 & 34 \\
\hline
\end{tabular}

Table 5 Lifetime values for $\mathrm{ZnS}$ and $\mathrm{ZnS}$ : 6\% Ca NPs under different excitation wavelengths.

\section{Conclusion}

A simple hydrothermal method was carried out to synthesize undoped and $\mathrm{Ca}^{2+}$ doped $\mathrm{ZnS}$ NPs with a maximal doping amount of $6 \mathrm{~mol} \%$. The physico-chemical, morphological and optical properties were investigated using XRD, SEM, TEM, Raman spectroscopy and luminescence technique. All samples exhibit a zinc sulfide blende-type structure as confirmed by X-Ray diffraction and Raman scattering, with particle sizes included in the range 6.0-8.3 nm, and 
demonstrated that $\mathrm{Ca}^{2+}$ ions are incorporated into the vacant sites leading to additional zinc deficiencies. Furthermore, the SEM/TEM analyses show that NPs present a micro-spherical structure.

PL excitation spectra show a characteristic band centered at $400 \mathrm{~nm}$ with no meaningful shifting from undoped to doped samples. PL emission spectra show a highly asymmetric and broadened emission band covering the whole visible region, with multiple contributions indicating the involvement of different luminescence centers in the radiative process. A Gaussian deconvolution shows the presence of two main bands for the non-doped sample due to intrinsic defects related to sulfur vacancies $\left(\mathrm{V}_{\mathrm{S}}\right)$ located at $20619 \mathrm{~cm}^{-1}(484 \mathrm{~nm})$ and zinc vacancies $\left(\mathrm{V}_{\mathrm{Zn}}\right)$ at $18692 \mathrm{~cm}^{-1}(535 \mathrm{~nm})$. In addition a third small band located at $16800 \mathrm{~cm}^{-1}(595 \mathrm{~nm})$ is observed for all doped samples and is attributed to the effect of the $\mathrm{Ca}^{2+}$ impurity. The best quantum efficiency for all samples is reached under $25000 \mathrm{~cm}^{-1}(400 \mathrm{~nm})$ wavenumber (wavelength) excitation. Lifetime measurements have confirmed the presence of two main transitions due to zinc and sulphur vacancies $\left(\mathrm{V}_{\mathrm{Zn}}, \mathrm{V}_{\mathrm{S}}\right)$. Variation of the excitation wavelength shows clearly that some contributions in the emission spectra can arise from the existence of impurities lying in the raw materials used in the synthesis process.

\section{Acknowledgements}

A.S. Messalti gratefully acknowledges the Algerian Ministry of Higher Education and Scientific Research (MESRS), the General Directorate of Scientific Research and Technological Development (DGRSDT) as well as the Ferhat Abbas Sétif 1 University for financial support. 


\section{References:}

[1] C.X. Liu, Y.Y. Ji, T.W. Tan, One-pot hydrothermal synthesis of water-dispersible ZnS quantum dots modified with mercaptoacetic acid, J. Alloys Compd. 570 (2013) 23-27.

[2] N.S. Nirmala Jothi, A.G. Joshi, R. Jerald Vijay, A. Muthuvinayagam, P. Sagayaraj, Investigation on one-pot hydrothermal synthesis, structural and optical properties of $\mathrm{ZnS}$ quantum dots, Mater. Chem. Phys. 138 (2013) 186-191.

[3] B. Poornaprakash, P.T. Poojitha, U. Chalapathi, S.H. Park, Achieving room temperature ferromagnetism in ZnS nanoparticles via Eu ${ }^{3+}$ doping, Mater. Lett. 181 (2016) 227-230.

[4] S.M. El-Bashir, Coumarin-doped PC/CdSSe/ZnS nanocomposite films: A reduced selfabsorption effect for luminescent solar concentrators, J. Lumin. 206 (2019) 426-431.

[5] Y.C. Zhang, G.Y. Wang, X.Y. Hu, W.W. Chen, Solvothermal synthesis of uniform hexagonal-phase ZnS nanorods using a single-source molecular precursor, Mater. Res. Bull. 41 (2006) $1817-1824$.

[6] Y. Wang, J. Li, J.S. Li, C.H. Duan, H.N. Zhang, H.M. Jian, L. He, G.H. Tao, C. Yan, T.G. Jiu, Solution prepared O-doped $\mathrm{ZnS}$ nanocrystals: Structure characterization, energy level engineering and interfacial applications in polymer solar cells, Sol. Energy 160 (2018) 353-359.

[7] Z.H. Xu, X.B. Tang, L. Hong, Y.P. Liu, D. Chen, Structural effects of ZnS: Cu phosphor layers on beta radio luminescence nuclear battery, J. Radioanal. Nucl. Chem. 303 (2015) 23132320.

[8] W.S. Ni, Y.J. Lin, Conduction behavior conversion for Cu-doped ZnS/n-type Si devices with different $\mathrm{Cu}$ contents, Appl. Phys. A 119 (2015) 1127-1132.

[9] S. Gupta, J.C. McClure, V.P. Singh, Phosphor efficiency and deposition temperature in ZnS: Mn A.C. thin film electroluminescence display devices, Thin Solid Films 299 (1997) 33-37. 
[10] M. Geszke, M. Murias, L. Balan, G. Medjahdi, J. Korczynski, M. Moritz, J. Lulek, R. Schneider, Folic acid-conjugated core/shell $\mathrm{ZnS}: \mathrm{Mn} / \mathrm{ZnS}$ quantum dots as targeted probes for two photon fluorescence imaging of cancer cells, Acta Biomater. 7 (2011) 1327-1338.

[11] R. Ban, J.J. Li, J.T. Cao, P.H. Zhang, J.R. Zhang, J.J. Zhu, Highly luminescent glutathionecapped $\mathrm{ZnS}: \mathrm{Mn} / \mathrm{ZnS}$ core/shell doped quantum dots for targeted mannosyl groups expression on the cell surface, Anal. Meth. 5 (2013) 5929-5937.

[12] M. Sajimol Augustine, A. Anas, A.V. Das, S. Sreekanth, S. Jayalekshmi, Cytotoxicity and cellular uptake of $\mathrm{ZnS}$ : $\mathrm{Mn}$ nanocrystals biofunctionalized with chitosan and amino acids, Spectrochim. Acta. A. Mol. Biomol. Spectrosc. 136 (2015) 327-333.

[13] K.B. Lin, Y.H. Su, Photoluminescence of $\mathrm{Cu}: \mathrm{ZnS}, \mathrm{Ag}$ : $\mathrm{ZnS}$, and $\mathrm{Au}: \mathrm{ZnS}$ nanoparticles applied in Bio-LED. Appl. Phys. B 113 (2013) 351-359.

[14] F. Amirian, M. Molaei, M., M. Karimipour, A.R. Bahador, A new and simple UV-assisted approach for synthesis of water soluble $\mathrm{ZnS}$ and transition metals doped $\mathrm{ZnS}$ nanoparticles (NPs) and investigating optical and photocatalyst properties, J. Lumin. 196 (2018) 174-180.

[15] D. Kakoti, P. Dutta, P. Gogoi, N. Dehingia, N. Rajkonwar, A. Boruah, A.T.T Mostako, P.K. Saikia, P.K. Gogoi, Corrigendum to: "Effect of $\mathrm{ZnS}$ nanoparticles on the Judd-Ofelt and radiating parameters of $\mathrm{Sm}^{3+}$ ions in sol-gel silica Matrix”, J. Lumin. 213 (2019) 451-453.

[16] C.S. Pathak, M. K. Mandal, Structural and optical properties of $\mathrm{Ca}^{2+}$ doped $\mathrm{ZnS}$ nanoparticles, Nanosci. Nanotechnol., Lett. 6(8) (2014) 681-684.

[17] L. El Mir, Luminescence properties of calcium doped zinc oxide nanoparticles Journal of Luminescence 186 (2017) 98-102.

[18] P. Visali, R. Bhuvaneswari, Photoluminescence and enhanced photocatalytic activity of $\mathrm{ZnO}$ nanoparticles through incorporation of metal dopants Al and Ca. Optik 202 (2020) 163706. 
[19] S. Suganya, M. Jothibas, S.J. Jeyakumar, Solid state synthesis of cadmium doped ZnS with excellent photocatalytic activity and enhanced visible light emission. J. Mater. Sci. Mater. Electron. 30 (2019) 7916-7927.

[20] S. Kakarndee, S. Juabrum, S. Nanan, Low temperature synthesis, characterization and photoluminescence study of plate-like ZnS, Mater. Lett. 164 (2016) 198-201.

[21] Q. Ma, Y.Q. Wang, J.H. Kong, H.X. Jia, Tunable synthesis, characterization and photocatalytic properties of various ZnS nanostructures, Ceram. Int. 42 (2016) 2854-2860.

[22] R.D. Shannon, C.T. Prewitt, Effective ionic radii in oxides and fluorides, Acta Crystallogr. B 25 (1969) 925-946.

[23] Z. Wei, Y. Lu, J. Zhao, S. Zhao, R. Wang, N. Fu, X. Li, L. Guan, F. Teng, Synthesis and Luminescent Modulation of ZnS Crystallite by a Hydrothermal Method, ACS Omega 3 (2018) $137-143$.

[24] D. K. Sen, S. Bhusha, Structural Studies of Some Zinc and Calcium Sulfide Phosphors Cryst. Res. Technol. 30(7) (1995) 943-947

[25] J. Gao, Y. Duan, C.M. Zhao, W. Liu, H. Dong, D. Zhang, H. Dong, Prediction of new ZnSCaS alloys with anomalous electronic properties. J. Mater. Chem. C7 (2019) 1246-1254.

[26] L.S. Birks, H. Friedman, Particle Size Determination from X- Ray Line Broadening, J. Appl. Phys. 17 (1946) 687-692.

[27] M. Pal, N.R. Mathews, E.R. Morales, J.M. Gracia y Jiménez, X. Mathew, Synthesis of $\mathrm{Eu}^{+3}$ doped $\mathrm{ZnS}$ nanoparticles by a wet chemical route and its characterization. Opt. Mater. 35 (2013) $2664-2669$.

[28] S. Dhara, A.K. Arora, S. Bera, J. Ghatak, Multiphonon probe in $\mathrm{ZnS}$ quantum dots, J. Raman Spectrosc. 41 (2010) 1102-1105. 
[29] R. Sarkar, C.S. Tiwary, P. Kumbhakar, S. Basu, A.K. Mitra, Yellow-orange light emission from $\mathrm{Mn}^{2+}$-doped $\mathrm{ZnS}$ nanoparticles, Physica E Low-Dimens. Syst. Nanostructures 40 (2008) $3115-3120$.

[30] S. Sapra, A. Prakash, A. Ghangrekar, N. Periasamy, D.D. Sarma, Emission Properties of Manganese-Doped ZnS Nanocrystals, J. Phys. Chem. B 109 (2005) 1663-1668.

[31] W. Chen, V.F. Aguekian, N. Vassiliev, A.Y. Serov, N.G. Filosofov, New observations on the luminescence decay lifetime of $\mathrm{Mn}^{2+}$ in $\mathrm{ZnS}: \mathrm{Mn}^{2+}$ nanoparticles, J. Chem. Phys. 123 (2005) 124707.

[32] B. Belache, Y. Khelfaoui, M. Bououdina, T. Souier, W. Cai, Photoluminescence of ZnS:Cu quantum dots embedded in silica thin films. J. Lumin. 207 (2019) 258-265.

[33] L. Hu, Y., Hu, B., Yang, D. \& Wei, Z. Suppression of blue photoluminescence and enhancement of green photoluminescence by $\mathrm{Mn}$ and $\mathrm{Cu}$ Co-doped $\mathrm{ZnS}$ quantum dots. J. Mater. Sci. Mater. Electron. 31 (2020) 2617-2624.

[34] T.P. Nguyen, Q.V. Lam, T.B. Vu, Effects of precursor molar ratio and annealing temperature on structure and photoluminescence characteristics of Mn-doped $\mathrm{ZnS}$ quantum dots. J. Lumin. 196 (2018) 359-367.

[35] S.J. Basha, V. Khidhirbrahmendra, J. Madhavi, U.S. Udayachandran Thampy, C.V. Reddy,

R.V.S.S.N. Ravikumar, Structural, optical, magnetic and thermal investigations on $\mathrm{Cr}^{3+}$ ions doped ZnS nanocrystals by co-precipitation method. J. Sci. Adv. Mater. Devices 4 (2019) 260-266.

[36] K.C. Kumar, N.M. Rao, S. Kaleemulla, G.V. Rao, Structural, optical and magnetic properties of Sn doped $\mathrm{ZnS}$ nano powders prepared by solid state reaction. Physica B Condens. Matter 522 (2017) 75-80. 
[37] M. Saleh, K.G. Lynn, L.G. Jacobsohn, J.S. McCloy, Luminescence of undoped commercial $\mathrm{ZnS}$ crystals: A critical review and new evidence on the role of impurities using photoluminescence and electrical transient spectroscopy, J. Appl. Phys. 125 (2019) 075702.

[38] P. Yang, M. Lu, D. Xu, D. Yuan, G. Zhou, Photoluminescence properties of ZnS nanoparticles co-doped with $\mathrm{Pb}^{2+}$ and $\mathrm{Cu}^{2+}$, Chem. Phys. Lett. 336 (2001) 76-80.

[39] U. Woggon, Optical properties of semiconductor quantum dots, Vol. 136, Springer Ed. (1996). 


\section{Highligths}

- $\mathrm{Ca}^{2+}$ doped ZnS NPs were synthesis by a facile hydrothermal method.

- PL excitation spectra show a characteristic band centered at $400 \mathrm{~nm}$.

- PL emission spectra show a large emission band covering the whole visible region.

- Deconvolution of luminescence spectra shows the presence of two main bands for the non-doped sample due to intrinsic defects related to $\mathrm{V}_{\mathrm{S}}$ and $\mathrm{V}_{\mathrm{Zn}}$.

- $\quad$ The $\mathrm{Ca}^{2+}$ doped materials show higher luminescence intensity, greater quantum yield and longer lifetime than undoped material. 


\section{Declaration of interests}

$\bigotimes$ The authors declare that they have no known competing financial interests or personal relationships that could have appeared to influence the work reported in this paper.

$\square$ The authors declare the following financial interests/personal relationships which may be considered as potential competing interests:

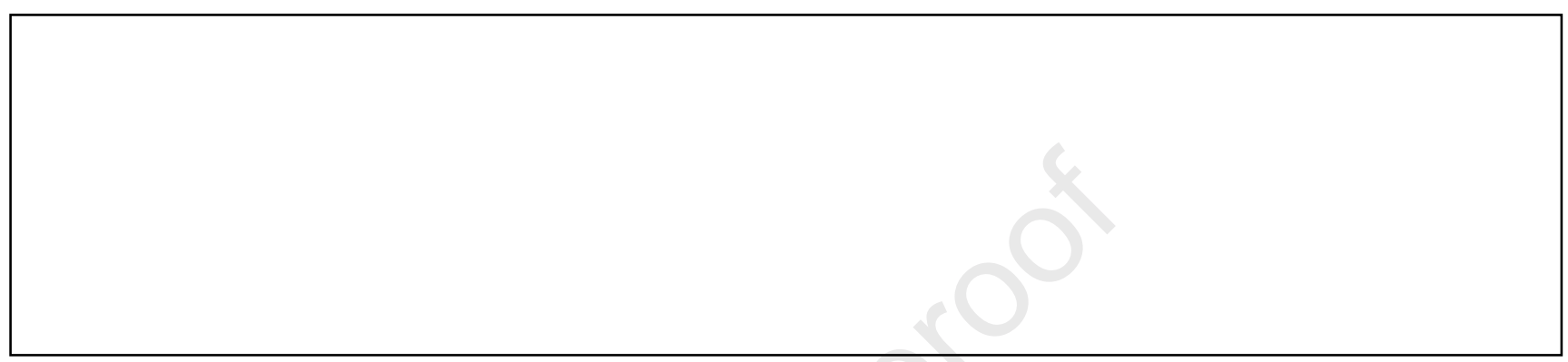

